Abstracta Iranica Iranica

Revue bibliographique pour le domaine irano-aryen

Volume 32-33 | 2013

Comptes rendus des publications de 2009-2010

\title{
Leonard Lewisohn (dir.). Hafiz and the Religion of Love in Classical Persian Poetry
}

Ève Feuillebois-Piérunek

\section{(2) OpenEdition}

1 Journals

Édition électronique

URL : http://journals.openedition.org/abstractairanica/40915

DOI : 10.4000/abstractairanica.40915

ISSN : 1961-960X

\section{Éditeur :}

CNRS (UMR 7528 Mondes iraniens et indiens), Éditions de l'IFRI

\section{Édition imprimée}

Date de publication : 1 décembre 2013

ISSN : 0240-8910

\section{Référence électronique}

Ève Feuillebois-Piérunek, «Leonard Lewisohn (dir.). Hafiz and the Religion of Love in Classical Persian Poetry », Abstracta Iranica [En ligne], Volume 32-33 | 2013, document 412, mis en ligne le 01 juillet 2016, consulté le 26 septembre 2020. URL : http://journals.openedition.org/abstractairanica/40915 ; DOI : https://doi.org/10.4000/abstractairanica.40915

Ce document a été généré automatiquement le 26 septembre 2020.

Tous droits réservés 


\title{
Leonard Lewisohn (dir.). Hafiz and the Religion of Love in Classical Persian Poetry
}

\author{
Ève Feuillebois-Piérunek
}

\section{RÉFÉRENCE}

Leonard Lewisohn (dir.). Hafiz and the Religion of Love in Classical Persian Poetry.

London/New York, I.B. Tauris, 2010, 330 p.

Dans ce travail d'édition de grande qualité, L. Lewisohn rassemble ici un très bel ensemble d'articles dédiés à Ḥāfez, de la plume de spécialistes renommés. Le tout forme une excellente introduction à l'étude de ce poète qui fut le plus fameux représentant du gazal persan et de ce que l'on peut appeler «la religion de l'amour». Les aspects philosophiques, théologiques et mystiques de la spiritualité de Ḥāfez, son enracinement dans une riche tradition littéraire qu'il a, à son tour, fertilisée, sa biographie envisagée dans les contextes historique et intellectuel de son époque sont ici analysés avec érudition, rigueur et sensibilité. Une copieuse bibliographie (p. 295-318), un index des noms, titres, lieux et thèmes et un index des termes techniques arabes et persans complètent l'ouvrage.

Le but principal poursuivi par les contributeurs était de connecter le lecteur occidental au «monde imaginal » de Ḥāfez, de lui offrir des clés pour accéder à la compréhension des symboles et des thèmes de l'œuvre complexe du poète, mais aussi de lui rendre justice en insistant sur les sources spirituelles et métaphysiques de ses enseignements sur l'amour, sources trop longtemps négligées ou minimisées.

Liste des articles :

\section{Part I : Hāäiz in the Socio-historical, Literary and Mystical Milieu of Medieval Persia :}

Leonard Lewisohn, "Prolegomenon to the Study of Hiâfiz" : Ce premier article plante en quelque sorte le décor, en reconstituant la Shiraz médiévale, rappelant le peu de l'on 
sait de la biographie du poète, et analysant sa relation aux divers princes ou grands dont les noms sont mentionnés dans ses poèmes: Hịâfez ne fut pas un panégyriste professionnel, ce qui ne l'empêcha pas de fréquenter les puissants de ce monde avec des fortunes diverses. Il explore ensuite les dimensions sociales, littéraires et métaphysiques d'un symbole privilégié, le libertin inspiré (rend), puis examine deux pratiques contemplatives prisées par le courant rendī: la contemplation amoureuse ( šāhed-bāzì) et l'art de la contemplation de la beauté humaine (naẓar-bāzī). Il en conclut que le poète professait l'éthique des "gens du blâme » (malāmatî) et étudie la louange des vagabonds spirituels (qalandar) dans son œuvre.

\section{Part II: Hiâfiz and the School of Love in Classical Persian Poetry :}

7 Husayn Ilahi-Ghomshei, "The Principles of the Religion of Love in Classical Persian Poetry" : L'A. passe en revue les thèmes et principes de la «religion de l'amour » dans les littératures soufies arabe et persane, et montre la longue lignée de ses représentants de Ḥallāj à 'Ayn al-Quḍāt Hamadānī et de Rūdakī à Sanā'î. Les mêmes doctrines apparaissent sous des formes diverses chez Ibn 'Arabī, 'Umar ibn al-Fārị̣, Neẓāmī, 'Ațțār, Sa'dī et Rūmī. Les différents termes poétiques désignant les tenants de ce courant spirituel sont définis et illustrés de citations, dans un esprit d'érudition plus que de synthèse. Ali Asghar Sey

8 ed-Gohrab, "The Erotic Spirit: Love, Man and Satan in Ḥâfiẓ's Poetry" : L'article s'intéresse à la combinaison de mythes, de traditions prophétiques, d'images bachiques et érotiques dans la théorie de l'amour de Ḥāfez, et montre qu'elle s'enracine dans la pensée d'Aḥmad Gazālī telle qu'elle s'exprime dans les Savāneḥ. Il insiste sur la nécessité de confronter la poésie de Ḥâfez avec les poésies ascétique, bachique et antinomique pour mieux la comprendre et la contextualiser.

9 Leili Anvar, “The Radiance of Epiphany: The Vision of Beauty and Love in Ḥăfiẓ's Poem of Pre-Eternity" : S'appuyant sur une analyse du thème du Jour du Covenant et de la Prééternité, l'A. s'intéresse au traitement par țāfez de thèmes importants comme l'amour, la beauté, le chagrin, la nostalgie, tout en montrant combien l'impact d'Ahmad Gazālī fut déterminant dans le choix de la poésie amoureuse comme véhicule de l'expérience mystique, le point commun entre ces deux termes étant leur ineffabilité et leur nature «supra-rationnelle».

\section{Part III: Hiăfiz and the Persian Sufi Tradition}

1 Charles-Henri de Fouchécour, "Ḥāfiz and the Sufi": L'A. insiste sur l'importance culturelle du XIVe s. qui vit l'expansion des ordres soufis au Moyen Orient, en Asie Centrale et en Inde. Il s'intéresse plus particulièrement aux thèmes bachiques qu'il estime en parfaite adéquation avec les définitions de termes techniques et l'herméneutique proposés par Maḥmūd Šabestarī dans le Jardin des Mystères. Il situe Ḥăfez dans le milieu soufi de son temps, révélant l'influence de son contemporain 'Emād Faqīh Kermānī. Il conclut qu'en dépit des fortes critiques à l'encontre des soufis dont est parsemé son Dìvān, Ḥāfez considérait le soufisme comme une voie bénéfique, à condition qu'elle amène au dépassement d'elle-même pour atteindre à la Loi de l'Amour.

Leonard Lewisohn, "The Religion of Love and the Puritans of Islam: Sufi Sources of Ḥāfiz̧'s Anti-Clericalism" : L'auteur examine l'antagonisme entre la piété ascétique et la religion de l'amour, entre l'ascète et le libertin. Le vice le plus grave est pour Ḥāfez comme pour Anșāin ou Ǵazālī avant lui, l'hypocrisie. L'éthique malāmatie et la 
théologie du péché plongent leurs racines dans la doctrine de Rašīd al-Dīn Maybodī et de Najm

al-Dīn Rāzì. Le point d'orgue de la doctrine morale de Ḥāfez est cependant l'insistance sur la miséricorde divine qui efface tout péché.

Carl W. Ernst, "Jalāl al-Dīn Davānī’s Interpretation of Ḥāfiẓ" : Davānī est un philosophe mystique qui vécut un siècle après Ḥāfez et composa le premier commentaire de sa poésie dans trois perspectives différentes : la philosophie mystique, le soufisme et la philosophie illuminative. Il y développe une herméneutique basée sur la lecture des symboles ou des mots comme des métaphores de réalités invisibles, à la manière de Šabestarī. Son travail s'apparente à celui effectué par les tenants de la waḥdat al-wujūd sur les poèmes d'Ibn al-Fāriḍ.

\section{Part IV: Ḥăfiz’s Romantic Imagery and Langage of Love}

Michael Barry, "The Allegory of Drunkenness and the Theophany of the Beloved in Sixteenth-Century Illustrations of Ḥāfiz" : À partir de l'analyse de deux miniatures d'époque timouride, M. Barry montre comment la taverne renvoie à une ivresse métaphysique emplissant l'univers entier, le vin étant le symbole de la Beauté divine et comment la Divinité se trouve figurée par une figure féminine de sagesse.

James Morris, "Transfiguring Love: Perspective Shifts and the Contextualization of Experience in the Ghazals of Ḥâfiz" : À travers l'analyse détaillé de deux gazals, Morris montre comment Ḥāfez glisse de l'abstrait au particulier et du discours général au message personnel, et s'efforce de reconstituer sa vision du monde comme théophanie de l'Un.

17 Franklin Lewis, "The Semiotic Horizons of Dawn in the Poetry of Ḥāfiz" : L'article étudie le topos de l'aube dans la poésie persane classique en général et les poèmes de Ḥāfez en particulier, tout en le comparant avec son traitement dans la littérature provençale où l'aube sonne l'heure de la séparation des amants, et dans la littérature arabe andalouse. Dans la littérature persane, ce thème apparaît pour la première fois chez Sanā'î. L'examen de la poésie de Ḥāfez montre que si le topos de l'aube, sans doute déjà devenu un cliché assez fade, a peu inspiré le poète, le mot « aube » apparaît cependant dans un cinquième des gazals comme élément contextuel et fait partie intégrale de son vocabulaire mythopoétique.

Parvin Loloi, "Hāfiz and the Language of Love in Nineteenth-Century English and American Poetry": L'A. se penche sur la réception de l'œuvre de Ḥāfez depuis les premières traductions en anglais de Sir William Jones en 1771 jusqu'à aujourd'hui. Elle montre comment ces traductions ont influencé les poètes romantiques allemands, anglais et américains, contribué au renouvellement des littératures occidentales, et inspiré la philosophie de l'amour de Shelley. 


\section{AUTEURS}

\section{ÈVE FEUILLEBOIS-PIÉRUNEK}

Université Sorbonne Nouvelle-Paris 3, Mondes iranien et indien, Paris 